\title{
Shifts of Emphasis
}

\section{Dear Reader,}

Contacts with the large engine industry during the preparation of this MTZindustrial brought home two points that deserve to be emphasised. In spite of the difficulties in the markets they serve, engine builders and their component suppliers have continued to invest. The fall in the price of oil has brought some relief to engine owners and operators, but we should bear in mind just how deep and long the current recession in world trade has become, with its double and even triple dips.

The readiness to plough back revenues applies not only to engines but also to the tools that are used to develop ever better products and the way they are developed. In their continued investments engine builders are helped by a business model in which the major revenue stream is spare parts and service, increasingly sold as package with a

new engine. As we see daily, the paradox that earnings are made after the engine is sold does not lessen pressure to improve the next generation and means there can be no thought of a "cash cow" mentality.

A recent invitation from MAN Diesel \& Turbo was illuminating. In this issue of MTZindustrial we can read how Niigata and Ural Diesel with FEV are using computer-based development tools and in Augsburg it was possible to see at first-hand how rapidly engine development processes are advancing. Underlining the digital revolution, many major advances are attributable to the march of the microprocessor. Open and closed-loop controls on the engine and their effect on performance are the outward manifestation of electronics in the large engine sector - indeed neither gas nor dual-fuel engines would run without them. But a tour of a development department makes it obvious how computer simulation and advanced calculation methods are accelerating progress and making the whole development process more efficient and cost-effective.

The tangible outcome of this progress is engines with new levels of performance - even including proud entries in the Guinness Book of Records. This all comes at an ideal time. Greenhouse gases are now as important a development criterion as noxious gases, and plans to raise the overall systems efficiency of ships are the next opportunity for the large engine industry to shine.

Following these most recent affirmations of internal combustion efficiency, the new CIMAC PR emphasis is right. The engine, shipping, power generation and railway industries should now go beyond declaring their readiness to be part of the solution. They must beat the drum, clear up a number of popular misapprehensions and underline their considerable achievements.
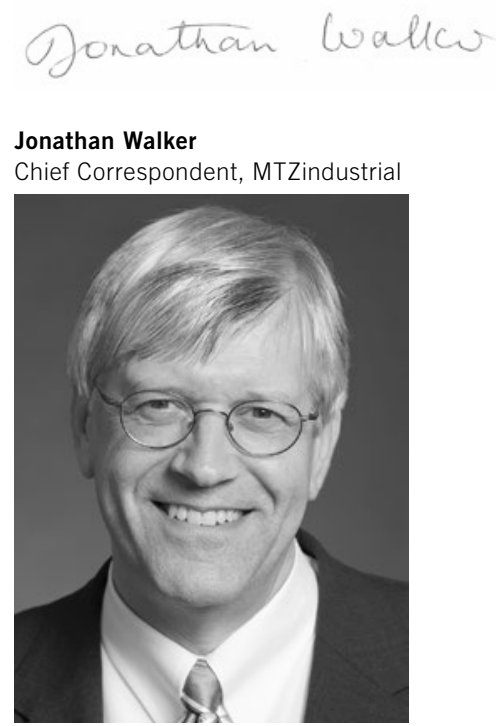